\title{
Considerações sobre o desempenho de estruturas de concreto pré-moldado em situação de incêndio
}

\author{
Considerations on the performance of precast concrete \\ structures in fire situation
}

\section{Cassiano da Silva Zago \\ Armando Lopes Moreno Junior Marcelo Cuadrado Marin}

\section{Resumo}

A crescente utilização do concreto pré-moldado para solução estrutural em diversas obras, como edificações industriais e comerciais, tornoutempo de construção. Porém, quando em situação de incêndio, determinadas características que esse sistema construtivo usualmente oferece como vantagens podem tornar-se uma desvantagem. Contando com espaços amplos, com grandes vãos livres, materiais combustíveis armazenados e ventilação apropriada, torna-se um cenário ideal para a propagação de um incêndio e consequente perda da capacidade de suporte da estrutura. Neste trabalho são apresentadas as implicações de um projeto que utiliza o concreto pré-moldado em situação de incêndio, além de levantar pontos para discussões sobre possibilidades que amenizem os riscos, tendo como base referências bibliográficas nacionais e internacionais, de uso corrente no meio técnico e acadêmico.

Cassiano da Silva Zago Universidade Estadual de Campinas Campinas - SP - Brasil

Armando Lopes Moreno Junior Universidade Estadual de Campinas Campinas - SP - Brasil

Marcelo Cuadrado Marin Leonardi Construção Industrializada Ltda. Atibaia - SP - Brasil

Recebido em 04/02/14 Aceito em 26/12/14
Palavras-chaves: Incêndio. Fogo. Concreto pré-moldado. Concreto pré-fabricado.

\section{Abstract}

The increasing use of precast concrete as a structural solution for different types of buildings, such as industrial and commercial buildings, has become a good, accessible choice, especially regarding construction time. However, in a fire situation, certain characteristics of this construction system that are normally considered as advantages could become disadvantages. With large spaces, large open spans, good ventilation and the storage of flammable materials, these buildings provide the ideal setting for fire spreading and the consequent loss of structure carrying capacity. In this study, we present the implications of a project that uses precast concrete in a fire situation, and we raise points for discussion on alternatives to mitigate risks, based on national and international bibliographic references currently used by the technical and academic community.

Keywords: Fire. Precast concrete. 


\section{Introdução}

Após alguns eventos ocorridos na década de 1970 , como o incêndio no edifício Andraus, em 1972, e no edifício Joelma, em 1974, houve o início da reformulação das medidas de segurança contra incêndios ${ }^{1}$ no Brasil. O reconhecimento dos órgãos responsáveissobre esse problema tornou possível acriação de leis e normas técnicas específicas.

De acordo com o código do consumidor, Lei n.8.078, art. 39, Seção IV - Das Práticas Abusivas, é vedado ao fornecedor de produtos ou serviços (BRASIL, 1990):

[...] colocar, no mercado de consumo, qualquer produto ou serviço em desacordo com as normas expedidas pelos órgãos oficiais competentes ou, se normas específicas não existirem, pela Associação Brasileira de Normas Técnicas ou outra entidade credenciada pelo Conselho Nacional de Metrologia, Normalização e Qualidade Industrial (CONMETRO).

Com a publicação da nova norma NBR 15200 (Projeto de estruturas de concreto em situação de incêndio) (ABNT, 2012), torna-se indispensável o estudo do comportamento dos elementos de concreto em situação de incêndio, principalmente os destinados a edificações industriais e comerciais nos quais usualmente é utilizado o concreto prémoldado. Vale advertir sobre a referênciaao emprego desse sistema construtivo na norma citada (ABNT, 2012, p. 1):

Para estruturas ou elementos estruturais pré-moldados ou pré-fabricados de concreto aplicam-se as exigências das Normas Brasileiras específicas. $\mathrm{Na}$ ausência de Norma Brasileira específica, aplicam-se as recomendações desta Norma [...].

Em virtude da escassez de trabalhos específicos que envolvam o concreto pré-moldado, destaca-se a importância da realização de estudos sobre o tema. Com esse foco, o objetivo deste trabalho é adiscussão da utilização desse sistema construtivoem situação de incêndio, tendo como base referências bibliográficas disponíveis atualmente no meio técnico e acadêmico.

São justificativas para o estudo do tema proposto:

(a) limitar o risco à vida humana, tanto dos ocupantes quanto da equipe de salvamento;

${ }^{1}$ Incêndio é ocasionado por uma reação em cadeia do fogo, ou seja, o momento em que o fogo não pode ser mais controlado, período denominado como flashover, é caracterizado como o início do incêndio.
- pela diminuição da exposição severa à fumaça ou ao calor e pelo eventual desabamento de elementos construtivos;

- reduzir a perda patrimonial; e

- destruição total ou parcial da edificação, estoques, documentos, equipamentos ou dos acabamentos dos edifícios da vizinhança;

(b) respeitar os aspectos legais e normativos aplicados à construção civil;

- Lei n. 8.078 (BRASIL, 1990): sobre os direitos dos consumidores;

- Lei n. 4.150 (BRASIL, 1962): institui o regime obrigatório de preparo e observância das normas técnicas nos contratos de obras e compras do serviço público de execução direta, concedida, autárquica ou de economia mista, através da associação Brasileira de Normas Técnicas, e dá outras providências;

- Decreto n. 56.819, de 10 de março de 2011 (POLÍCIA..., 2011): institui o regulamento de segurança contra incêndio das edificações e áreas de risco no estado de São Paulo e estabelece outras providências;

- NBR 15200 (ABNT, 2012): Projeto de Estruturas de Concreto em Situação de Incêndio; e

- NBR 14432 (ABNTM 2001): Exigências de resistência ao fogo de elementos construtivos de edificações - Procedimento.

Esses documentos, e outros não citados, são exemplos da preocupação atual referente a estruturas em situação de incêndio. Desse modo, é de interesse profissional e acadêmico que este tema seja abordado com a ênfase que merece.

\section{Fundamentos da engenharia de segurança contra incêndio}

No estudo da segurança contra incêndio, qualquer elemento que requer uma classificação de resistência ao fogo deveseguir ostrês requisitos fundamentais, que são resistência estrutural ao fogo (R), estanqueidade (E) e isolamento (I), referentes respectivamente à estabilidade estrutural ante o incêndio, sendo esta capaz de suportar as variações de temperatura, dilatações inferidas e alterações nas propriedades mecânicas dos materiais; à estanqueidade do ambiente, para não ocorrer o alastramento tanto dos gases tóxicos quanto das chamas para outras regiões da edificação; e ao isolamento térmico, para manter as altas temperaturas confinadas no ambiente do sinistro (BUCHANAN, 2002; PURKISS, 2007). 
Para estruturas que possuem ambientes com grandes dimensões e em muitos casos bem ventilada, como acontece em algumas estruturas em concreto pré-moldado, há grande preocupação com as exigências desses requisitos. Além disso, a compreensão gerada pelos estudos sobre a propagação do incêndio também é fundamental. Fazendo uma comparação para evidenciar esse fato, mesmo para edificações idênticas e com materiais combustíveis semelhantes armazenados, a propagação de um incêndio não ocorre do mesmo modo. Isso se deve a diversos fatores geográficos e climáticos, como umidade relativa do ar, temperatura ambiente, massas de ar diferenciadas e pressão atmosférica.

Neste estudo é dado maior enfoque às variáveis que possuem maior controle, a saber:

(a) carga de incêndio: todos os tipos de materiais combustíveis armazenados na edificação, como mobiliário, equipamentos, revestimentos da edificação e produtos armazenados;

(b) forma do edifício: como exemplo, um edifício de pequena altura e com grande área de piso possui maior risco que um edifício com múltiplos pavimentos e com compartimentações internas;

(c) condições de ventilação: disposição, tamanho e posição das aberturas, podendo ser janelas, portas, shafts, lanternins e poço de elevador;

(d) isolamento térmico do ambiente: quanto mais isolantes os materiais das paredes, teto e piso (elementos que envolvem o ambiente), menor a transferência de calor entre ambientes separados por esses elementos, reduzindo, assim, a propagação do incêndio; e

(e) proteção ativa: a probabilidade de início de um incêndio é reduzida em edifícios com detectores de fumaça, sistema de chuveiros automáticos, brigada contra incêndio e compartimentação adequada.

A partir dessas variáveis, é possível desenvolver curvas de crescimento de temperatura pelo tempo ao qual os elementos estruturais estarão sujeitos. Entre as possíveis curvas, pode-se citar: curva de incêndio natural, em que é retratado o aumento de temperatura pelo tempo de forma real; curva de incêndio padrão, curva padronizada por normas técnicas geralmente representadas por equações, e curva de incêndio de projeto, que representa o ambienteem situação de incêndio, criada por meio dos dados listados acima (MORENO JUNIOR; MOLINA, 2012).

A complexidade do uso da curva de incêndio natural justifica a necessidade da utilização de curvas mais simplificadas, como a curva de incêndio padrão. Para isso, a International Organization for Standardization (ISO) estabeleceu uma curva padrão de crescimento de temperatura pelo tempo ao qual os materiais deveriam estar sujeitos e, assim, ter uma classificação de resistência ao fogo. Essa curva padrão, denominada como curva padrão ISO 834, foi absorvida nas normas nacionais e hoje é utilizada para a avaliação dos elementos estruturais.

Como proposto pela norma, os elementos estruturais devem possuir uma classificação de segurança contra incêndio que é medida pelo tempo. Por exemplo, um elemento classificado com um TRRF $^{2}$ de 60 min deve ser capaz de resistira um tempo de 60 min exposto ao incêndio padrão. Deve-se atentar que essa classificação diz respeito apenas à curva padrão utilizada, e não a uma curva de incêndio real; desse modo, não diz respeito ao tempo total em que a estrutura esteve exposta ao incêndio, como também não diz respeito ao tempo de saída dos ocupantes da edificação, nem da chegada do corpo de bombeiros.

A classificação do tempo requerido de resistência ao fogo (TRRF) dos elementos estruturais é encontrada na NBR 14432 (ABNT, 2001) e na IT:08 do Corpo de Bombeiros (POLÍCIA..., 2001). Seus valores para o dimensionamento fornecem uma segurança aceitável, levando em conta as probabilidades de ruína diantede uma situação de incêndio durante a vida útil da edificação.

Abaixo, na Figura 1, a curva ISO 834 utilizada pelas normas brasileiras.

A curva ISO 834 é fundamentada no aumento de temperatura pelo tempo, tendo materiais celulósicos como combustíveis ${ }^{3}$. A construção matemática dessa curva dá-se pela seguinte Equação 1:

$\theta_{g}-\theta_{g_{0}}=345 \log (8 t+1)$

Eq. 1

Onde:

$\theta_{g}=$ temperatura dos gases atmosféricos no compartimento no instante $\mathrm{t}\left[{ }^{\circ} \mathrm{C}\right]$;

$\theta_{g_{0}}=$ temperatura dos gases atmosféricos no compartimento no instante $\mathrm{t}=0\left[{ }^{\circ} \mathrm{C}\right]^{4}$; e

$t=$ tempo considerado [min].

\footnotetext{
${ }^{2}$ TRRF, tempo requerido de resistência ao fogo, é o tempo mínimo de resistência ao fogo de um elemento construtivo sujeito ao incêndio padrão preconizado por normas e leis vigentes (ABNT, 2012).

${ }^{3}$ Para outros materiais combustíveis, é aconselhável a utilização de curvas alternativas.

${ }^{4}$ Como simplificação, esse valor pode ser tomado como igual a 20 ${ }^{\circ} \mathrm{C}$
} 
Figura 1 - Curva de incêndio padrão ISO 834

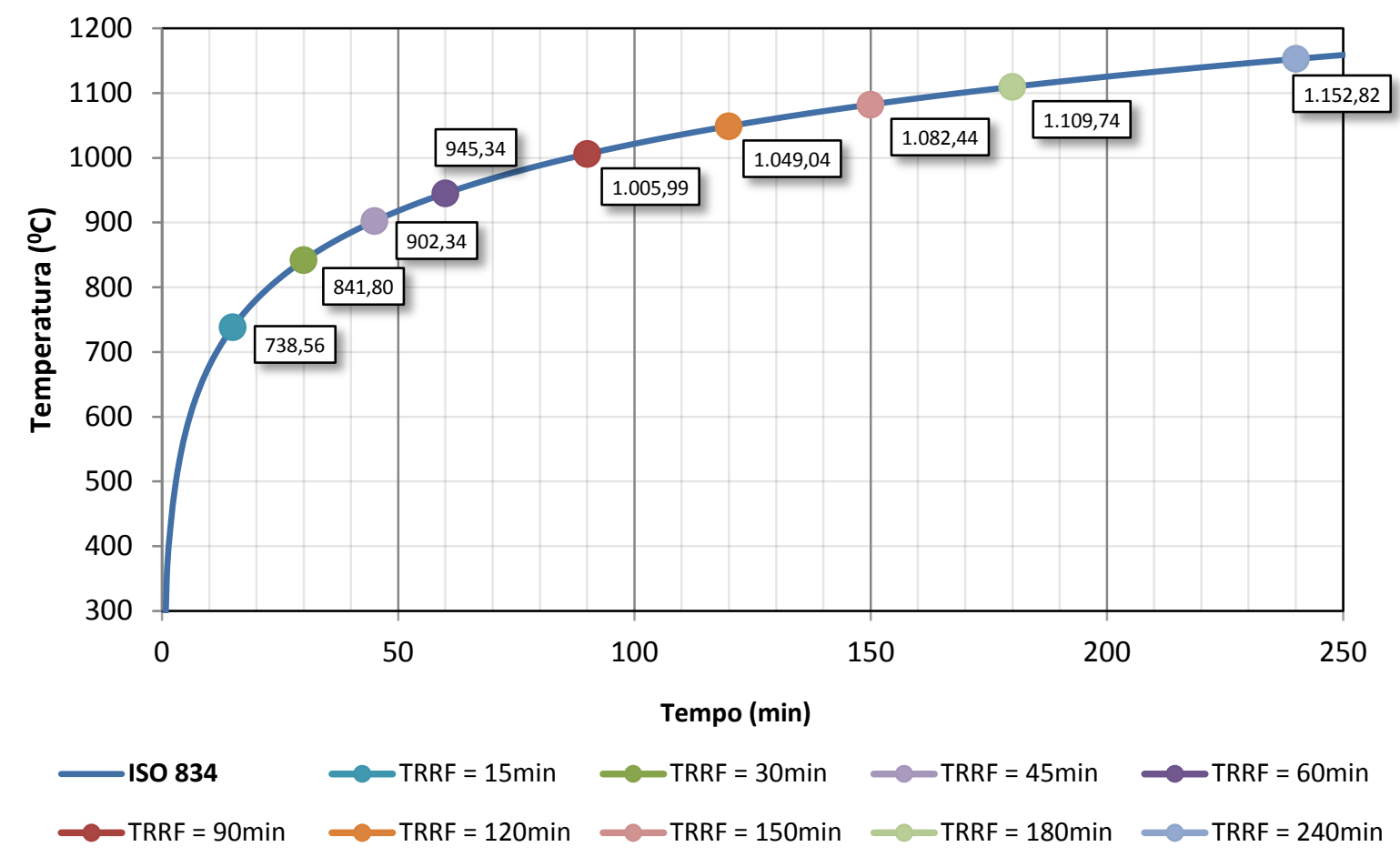

Apesar da adoção da curva ISO 834 nas normas brasileiras, há a possibilidade da utilização de procedimentos ou normas internacionais que possuam outras curvas padrão, tais como Curva ASTM E119 (AMERICAN..., 1995), Curva "H",5 (EUROPEAN..., 2002), Curva de incêndio externa (EUROPEAN..., 2002), Curvas de incêndio de projeto, etc., desde que aplicáveis e aceitáveis pela comunidade técnica e científica.

As curvas paramétricas, que representam a evolução da temperatura com o tempo por meio de modelos matemáticos que buscam a realidade do incêndio de fato, são denominadas de curva de incêndio de projeto. Para a simulação dessas curvas, deve-se ter o conhecimento do comportamento dos materiais ao fogo (composição química, forma física, área superficial exposta e inércia térmica) e dos fatores intrínsecos ao ambiente onde esses materiais estão (tipo de uso da edificação, ventilação e elementos de compartimentação) (MORENO JÚNIOR; MOLINA, 2012).

A adoção de curvas de incêndio de projeto é uma alternativa para grandes edificações que possuem compartimentações de usos diferenciados e que buscam maior economia de materiais, utilizando, assim, para cada ambiente, uma curva específica. Como exemplo, pode-se citar uma grande edificação em concreto pré-moldadoque possua áreas de escritório, depósito, indústria, almoxarifado e vestiário, todas compartimentadas com paredes ou painéis corta-fogo, tendo então uma curva de incêndio de projeto para cada ambiente.

Assim como a norma europeia, as normas técnicas brasileiras poderiam incorporar curvas de incêndio de projeto para algumas análises estruturais em específico. Como exemplo, segue a Equação 2 de curva de incêndio de projeto proposta no Anexo A do Eurocode 1 (EUROPEAN..., 2002) para compartimentos de até $500 \mathrm{~m}^{2}$ de área de piso sem aberturas na cobertura e para alturas máximas de compartimento de $4 \mathrm{~m}$, onde se assume que a carga de incêndio do compartimento seja totalmente consumida.

$\Theta_{g}=20+1325\left(1-0,324 e^{-0,2 t^{*}}-0,204 e^{-1,7 t^{*}}-\right.$ $\left.0,472 e^{-19 t^{*}}\right)$

Eq. 2

Neste trabalho não é especificada cada variável dessa equação devido a sua complexidade, porém se pode encontrar toda a teoria no Anexo A da referida norma.

${ }^{5}$ Curva padrão para materiais à base de hidrocarbonetos.

52 Zago, C. da S.; Moreno Junior, A. L.; Marin, M. C. 


\section{Estruturas em concreto pré- moldado em situação de incêndio}

\begin{abstract}
A pré-moldagem é caracterizada como um processo de construção em que a obra, ou parte dela, é moldada fora de seu local de utilização definitivo. Frequentemente a prémoldagem é relacionada a outros dois termos: a pré-fabricação $e \quad a$ industrialização da construção. (EL DEBS, 2000).
\end{abstract}

Diferentemente das construções de concreto moldado no local, o pré-moldado merece atenção especial quanto a sua análise e dimensionamento. Isso se deve às condições impostas ao elemento desde sua fabricação, passando por transportes e montagem, até sua utilização.

$\mathrm{Na}$ fase de utilização da estrutura, as verificações adotadas são o dimensionamento das ligações entre os elementos, o comportamento dos elementos isoladamente e no conjunto global, a verificação ante o colapso progressivo da estrutura com possíveis mudanças no esquema estático e incertezas quanto às transmissões de forças nas ligações entre elementos (EL DEBS, 2000). Além dessas verificações, o responsável técnico deve somar a verificação anteas ações de caráter excepcional, como ações sísmicas e ações devidas ao incêndio.

Algumas edificações, tais como edifícios
altos, grandes depósitos, centros de
compras, instalações industriais e tantas
outras necessitam de projetos
diferenciados, pois envolvem grandes
riscos, sendo que no Brasil essas
construções não têm obedecido a todas as
exigências, falhando em algum ponto do
projeto, da construção ou da operação,
colocando em risco, em caso de sinistro,
ocupantes e bombeiros envolvidos. (DEL
CARLO, 2008).

De acordo com Vargas e Silva (2003, p. 14), uma estrutura segura em situação de incêndio

\section{[...] é aquela que, com ou sem proteção contra incêndio, tem grande probabilidade de resistir aos esforços solicitantes em temperatura elevada, de forma a evitar o seu colapso[...].}

Tratando-se da segurança contra incêndios para o concreto pré-moldado, deve-se lidar com o mesmo problema dos outros sistemas construtivos, que são resistência (R), estanqueidade (E) e isolamento (I), tratados nas seções a seguir.

\section{Resistência}

No quesito resistência, o fator inicial deve-seà análise estrutural, que, por sua vez, é regida pelas teorias de estática e de resistência dos materiais. Em situação de incêndio, essas teorias continuam válidas e aplicáveis, tendo como diferença as ponderações de ações em caráter excepcional e as características físicas, químicas e mecânicas em que os materiais dos elementos estruturais se encontram (ALBUQUERQUE et al., 2012; COSTA, 2008).

De acordo com as normas NBR 6118:2007 e NBR 8681:2004, a análise última da estrutura em situação de incêndio será do tipo excepcional ${ }^{6}$, que corresponde à Equação 3:

$F_{d, f i}=\gamma_{g} F_{g k}+F_{q e x c}+\gamma_{q} \sum_{2}^{n} \psi_{2 j} F_{q j k}$

Eq. 3

Como alternativa, pode-se realizar uma verificação que leve em conta a redução da resistência mecânica dos materiais e a capacidade dos elementos estruturais, mediante a Equação 4:

$S_{d, f i}=\left(\gamma_{g} F_{g k}+\gamma_{q} \sum_{2}^{n} \psi_{2 j} F_{q j k}\right) \leq$

$R_{d, f i}\left[f_{c k, \theta}, f_{y k, \theta}, f_{p y k, \theta}\right]$

Eq. 4

Os coeficientes de ponderação $\gamma_{g}, \gamma_{q} \mathrm{e}$ $\psi_{2}$ sãofornecidospelanorma NBR 6118 (ABNT, 2014).

Nota-se que na utilização do coeficiente $\psi_{2}$ as ações de vento serão multiplicadas por um valor nulo, tendo como consequência na avaliação da estrutura uma redução considerável nas condições de não linearidade geométrica. Do mesmo modo, para a análise das cargas acidentais, pode-se utilizar um fator redutor ${ }^{7}$ desse coeficiente; porém, por tratar-se de edificações comerciais ou industriais, fica a cargo do responsável pelo projeto a utilização desse fator de redução, uma vez que, para esses casos, pode não ocorrer a ponderação estatística, ou seja, a sobrecarga poderá estar em plena carga.

Seguindo os procedimentos normativos da NBR15200 (ABNT, 2012), pode-se realizar os seguintes métodos de cálculo: método tabular,método de cálculo simplificado, método de cálculo avançado e método experimental.

Apesar de os métodos de cálculo serem aplicáveis para a análise e dimensionamento estrutural, estudos investigativos apresentam alguns fatores que devem ser levados em conta nesse tipo de

\footnotetext{
${ }^{6}$ Estruturas são projetadas e dimensionadas para resistir incêndios não intencionais, ou seja, em outra situação, criminosa ou terrorista, foge da condição excepcional como proposto pela norma (COSTA, 2008).

${ }^{7}$ De acordo com a norma NBR 8681 (ABNT, 2004), para combinações excepcionais em que a ação principal for o fogo, o
} coeficiente $\Psi_{2}$ pode ser reduzido multiplicando-o por 0,7 . 
avaliação, como o efeito do spalling para diferentes classes de resistência do concreto, a avaliação da interface aço-concreto, os efeitos de dilatações térmicas, variações bruscas de temperatura no controle do sinistro e a estabilidade global da estrutura.

De acordo com Kirchhof et al. (2011), o fenômeno conhecido como spalling explosivo ocorre devido à reduzida porosidade do material, que dificulta a saída do vapor de água gerada pelo aquecimento, tendo assim um acréscimo de pressão interna e o surgimento de tensões de tração que superam a resistência do concreto ${ }^{8}$. Em seu trabalho, encontram-se ensaios de corposdeprova com classe de resistência acima dos 40MPa. Nos resultados, foi constatado queo aumento do teor de umidade no corpo de prova foium fator prejudicial devido ao aumento do efeito spalling. Outra hipótese tratada pelos autores diz respeito à diminuição da porosidade com o aumento da resistência, que é outro possível fator prejudicial, contudo não analisado experimentalmente.

Nesta questão sobre o spalling, é fundamental buscar mecanismos que reduzam seu efeito, mas sem alterar o aspecto econômico-financeiro da edificação. Como opção, podem-se utilizar fibras de polipropileno na mistura de concreto, já que em altas temperaturas ocorre a degradação dessas fibras, criando-se canais para o alívio da pressão interna. Castro, Tiba e Pandolfelli (2011) fazem uma revisão abrangente sobre a utilização dessas fibras em concreto de alto desempenho submetido a altas temperaturas.

Devido ao fato de os coeficientes de dilatação térmica do concreto e do aço serem similares, para uma pequena variação de temperatura ambiente não ocorre tensões entre a interface desses materiais. Porém, em temperaturas elevadas, esses coeficientes distanciam-se em até 30 vezes, causando tensões que podem levar a fissuras e à perda do elemento concreto armado (CÁNOVAS, 1988). Essas tensões podem ser definidas como um limite de temperatura no qual a armadura se encontra. A norma Eurocode 2 (EUROPEAN..., 2004) prescreve algumas temperaturas críticas de diferentes tipos de aço (SILVA, 2012):

(a) barras protendidas: $400{ }^{\circ} \mathrm{C}$;

(b) fios e cordoalhas protendidas: $350^{\circ} \mathrm{C}$; e

(c) barras de aço convencionais para o concreto armado: $500^{\circ} \mathrm{C}$.

Como exemplo, testes feitos em uma série de lajes alveolares protendidas a altas temperaturas

${ }^{8}$ Informações sobre o efeito do spalling podem ser encontradas no manual da FIB 38 (FÉDÉRATION..., 2007). apresentaram falhas devido ao "escorregamento" da armadura, aliviando, assim, sua protensão (ANDERSEN; LAURISDEN, $19999^{9}$ apud BUCHANAN, 2002). Devido a esse problema, houve diminuição de resistência ao cisalhamento, causando falha prematura. Resultados semelhantes foram observados em outros testes (FONTANA; BORGOGNO, $1995^{10}$ apud BUCHANAN, 2002). Contudo, esse fato não tem sido observado em situações reais de incêndio. A consideração do comportamento do plano de laje como um septo rígido (ou diafragma rígido), com a utilização de barras de reforço longitudinais e transversais na capa e alvéolos, torna os elementos mais resistentes ao incêndio, atenuando, assim, seu colapso (FÉDÉRATION..., 2008).

A norma NBR 15200 (ABNT, 2012) propõe que os esforços decorrentes de deformações impostaspelo incêndio, com base na curva padrão, podem ser desprezados. Essa hipótese é adotada como sendo favorável à segurança para as simplificações impostas quanto à dilatação, no entanto sem demonstrações (SILVA, 2012).

De acordo com o manual da FIB n. 43 (FÉDÉRATION..., 2008), uma situação crítica ocorre quando o fogo cobre uma larga superfície, resultando em grandes deformações acumuladas. Nesse caso é possível assumir que, tomando uma grande área de piso, a deformação longitudinal acumulada em tramos sucessivos pode chegar a $100 \mathrm{~mm}$ ou mais. Esse tipo de análise é recomendável quando utilizados modelos mais realistas de incêndio. Levando em conta essas dilatações, o comportamento não linear pode ser importante sob condições de incêndio devido à redução da resistência mecânica dos materiais e às deformações impostasà estrutura.

$\mathrm{Na}$ situação de combate a incêndio, os elementos estruturais devem suportar o rápido resfriamento causado pela ação dos bombeiros para conter o incêndio, ação que produz contrações repentinas, causando danos ao elemento estrutural (CÁNOVAS, 1988). Souza e Moreno Junior (2010) realizaram ensaios de resistência mecânica em corpos de prova de concreto submetidos a altas temperaturas e, entre outros objetivos, buscaram comparar os efeitos do arrefecimento abrupto com água e do arrefecimento ao ar livre. A partir dos resultados, concluíram que ocorre maior dano nas propriedades mecânicas do concreto quando resfriado abruptamente com água.

\footnotetext{
${ }^{9}$ ANDERSEN, N. E.; LAURISDEN, D. H. "TT-roof slabs". "Hollow core concrete slabs". Denmark: Danish Institute of Fire Technology, 1999. Technical Report X52650, Parts 1 and 2 respectively.

10FONTANA, M; BORGOGNO, W. Brandverhalten von Slim-FloorVerbunddecken. Stahlbau, Berlin, v. 64, p. 168-174, 1995.
} 
Ligações pré-moldadas do tipo articuladas, ou do tipo apoio simples de gravidade, não necessitam de tratamento especial, uma vez que o pino chumbador está bem protegido pelo concreto, tendo assim grande vantagem quanto à resistência ao fogo. Já para ligações do tipo semirrígida, ou ligações do tipo mola, por se tratar em alguns casos da estabilidade global da estrutura, como edificações altas com diversos pavimentos, o cálculo deverá ser criterioso, uma vez que ocorre aumento de esforços de momentos negativos no apoio devido à diminuição da rigidez da viga. $\mathrm{O}$ cálculo deverá seguir os mesmos princípios e soluções aplicadas para os elementos estruturais de concreto, como dimensões mínimas para a seção transversal e cobrimento suficiente para a armadura.

A proteção dos elastômeros não é exigida, já que sua deterioração não causa o colapso do elemento; contudo, após o incêndio é recomendável sua substituição. Para as demais conexões, como cantoneiras ou perfis metálicos para o apoio de vigas ou lajes, estas deverão ser protegidas com a mesma classe de resistência ao fogo que o exigido pela estrutura circundante. Seu dimensionamento depende da resistência do aço ante o fogo e da intensidade e duração do incêndio. Do mesmo modo, a ancoragem das cordoalhas com sistema de pós-tensão deverá ser protegida com a mesma classe de resistência ao fogo que o exigido pela estrutura.

\section{Estanqueidade}

A estanqueidade é exigida em todos os tipos de construções e tem a função de evitar o alastramento tanto dos gases tóxicos quanto das chamas para outras regiões da edificação. Aberturas que estão desprotegidas podem reduzir a resistência ao fogo do ambiente e fornecer caminhos para o alastramento do incêndio. Alguns códigos de construção sugerem requisitos para esses casos.
As juntas estruturais entre os elementos prémoldados devem ser concebidas e detalhadas de forma a respeitar as condições impostas ao incêndio. Para isso, o Eurocodel (EUROPEAN..., 2002) recomenda que as larguras nas juntas não excedam o limite de $20 \mathrm{~mm}$ e não tenham mais que a metade da espessura do elemento, como mostrado na Figura 2.

Tendo como principais pesquisadores Gustaferro e Martin (PRESTRESSED..., 2011), o manual do PCI aborda esse assunto de maneira mais abrangente que a norma europeia. Seguem as recomendações encontradas nesse documento.

A resistência ao fogo das juntas é influenciada pelo tipo da junta, tipo de material utilizado na junta, sua largura e espessura do painel. De acordo com ensaios comprobatórios, os pesquisadores citados mostraram que, ao fornecer a espessura apropriada dos materiais de isolamento no interior da junta, é possível atingir a mesma classe de resistência ao fogo que a dos painéis corta-fogo. Gráficos de requisitos mínimos de espessura e tipo de materiais são encontrados de forma detalhada no manual.

Outro fator abordado no manual diz respeito às juntas entre lajes alveolares. A utilização das capas de concreto moldadas in loco traz grande benefício para a resistência ao fogo, uma vez que o concreto sela a chave de cisalhamento ${ }^{11}$.

Para o caso de pavimentos que não utilizam a capa de concreto moldada in loco, as juntas podem ser preenchidas com argamassa, e não há a necessidade do preenchimento completo, apenas da espessura da mesa superior da laje alveolar.

\section{Isolamento}

Para este requisito, o elemento construtivo deverá ter a capacidade de impedir, em sua face não exposta ao fogo, um incremento de temperatura maior que $140^{\circ} \mathrm{C}$, na média dos pontos de medida, ou temperaturas maiores que $180^{\circ} \mathrm{C}$ em qualquer ponto de medida (ABNT, 2001).

Figura 2- Dimensões das aberturas das juntas

Fonte: European Committee for Standardization (2004).

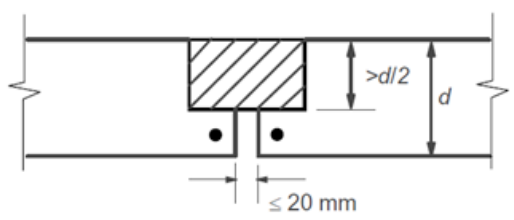

${ }^{11}$ Chave de cisalhamento é o elemento estrutural formado por concreto, graute ou argamassa para o preenchimento da junta longitudinal entre as lajes alveolares, que promove a solidarização e a transmissão de esforços entre elas. 
No sistema construtivo em concreto pré-moldado, os elementos que possuem maior preocupação quanto a essa imposição são os painéis e as lajes alveolares. Os primeiros podem ser utilizados como uma peça maciça de concreto, como painéis sanduíches ou alveolares. Desde que dimensionados para esse fim, todas as opções de painéis podem ser utilizadas como elementos corta-fogo, interna ou externamente à edificação.

O painel sanduíche é composto de duas placas de concreto que envolvem um material isolante, o qual pode ser um composto resistente ao fogo ou apenas um espaço vazio, desde que o conjunto atenda aos requisitos de isolamento. O manual do PCI (PRESTRESSED..., 2010) sugere para esse tipo de elemento a seguinte Equação 5, na qual levam em conta o comportamento ao incêndio de diversos tipos de materiais em conjunto:

$R=\left(R_{1}^{0,59}+R_{2}^{0,59}+\cdots+R_{n}^{0,59}\right)^{1,7}$

Eq. 5

Onde:

$\mathrm{R}$ é a resistência ao fogo do conjunto, em minutos; $\mathrm{e}$

$R_{1}, R_{2}$ e $R_{n}$ são as resistências individuais de cada elemento, em minutos.

Com relação às lajes alveolares, estas são frequentemente utilizadas como lajes de pisos, embora possam ser utilizadas na posição vertical, como elementos de compartimentação. De acordo com a norma EN 1168:2005+A3:2011 (EUROPEAN..., 2008), o dimensionamento pode ser realizado, seguindo as recomendaçõesda norma Eurocode2 (EUROPEAN..., 2004), com a utilização dos ábacos de lajes maciças ${ }^{11}$. Como ressalva, o cálculo deverá utilizar uma espessura equivalente, conforme a seguinte Equação 6 :

$t_{e}=h \sqrt{\frac{A_{c}}{b h}}$

Eq. 6

Onde:

$t_{e}$ é a espessura equivalente de laje maciça;

$h$ é a espessura da laje alveolar;

$A_{c}$ é a área líquida da seção de concreto; e

$b$ é a largura da laje.

Na Tabela 1 são apresentadas as resistências ao fogo das lajes alveolares, e na Tabela 2, valores para a verificação do elemento ante o cisalhamento.

Na Figura 3 são apresentadas as temperaturas internas das lajes alveolares ante o incêndio padrão e as definiç̧ões das variáveis utilizadas no cálculo.

Como alternativa de análise, encontram-se no manual do PCI (PRESTRESSED..., 1998) algumas recomendações auxiliares quanto ao projeto e ao dimensionamento das lajes alveolares. Do mesmo modo que a norma alemã, o manual apresenta gráficos para o auxílio do dimensionamento com base na espessura equivalente. Essa espessura é calculada dividindo-se a área líquida da seção transversal da laje alveolar pela sua largura.

$\mathrm{Na}$ Figura 4 são apresentadas as informações referentes ao tempo de resistência das lajes alveolares. O gráfico da esquerda representa o tempo de resistência ao fogo de lajes sem qualquer tipo de proteção, e, no gráfico da direita, os tempos de resistência de lajes com a adição de capas de concreto moldadas in loco.

Tabela 1 - Tabela para pré-dimensionamento de lajes alveolares em situação de incêndio

\begin{tabular}{ccccc}
\hline \multirow{2}{*}{ Dimensões mínimas } & \multicolumn{4}{c}{ Classe de resistência ao fogo exigida } \\
\cline { 2 - 5 } & REI 60 & REI 90 & REI 120 & REI 180 \\
\hline $\begin{array}{c}\text { Espessura mínima } \\
\text { da laje (mm) }\end{array}$ & 130 & 160 & 200 & 250
\end{tabular}

Nota:(1) A espessura mínima da laje baseia-se numa área mínima de concreto de 0,4 bh; e(2) Quando for utilizada uma camada não combustível sobre o piso (camada de concreto ou de argamassa), sua espessura pode ser levada em conta na resistência ao incêndio como função de compartimentação. 
Tabela 2 - Dados tabelados para a resistência ao cisalhamento $V_{\boldsymbol{R} \boldsymbol{d}, \boldsymbol{f} i}$

\begin{tabular}{ccccc}
\hline $\begin{array}{c}\boldsymbol{V}_{\boldsymbol{R}, \boldsymbol{f i} \boldsymbol{i}} \\
\boldsymbol{V}_{\boldsymbol{R d}}(\%)\end{array}$ & \multicolumn{5}{c}{ Classe de resistência ao fogo } \\
\hline Espessura da laje (mm) & REI 60 & REI 90 & REI 120 & REI 180 \\
\hline $\mathbf{1 6 0}$ & $70 \%$ & $65 \%$ & $60 \%$ & $45 \%$ \\
$\mathbf{2 0 0}$ & $65 \%$ & $60 \%$ & $60 \%$ & $50 \%$ \\
$\mathbf{2 4 0 - 2 8 0}$ & $60 \%$ & $60 \%$ & $55 \%$ & $50 \%$ \\
$\mathbf{3 2 0}$ & $60 \%$ & $55 \%$ & $50 \%$ & $45 \%$ \\
$\mathbf{3 6 0 - 4 0 0}$ & $55 \%$ & $50 \%$ & $50 \%$ & $45 \%$ \\
\hline
\end{tabular}

Nota: (1) Tabela utilizada para lajes alveolares com protensão inicial; (2) Laje apoiada em $70 \mathrm{~mm}$ de cada lado; (3) Área de aço de $1,88 \mathrm{~cm}^{2} / \mathrm{m}$ à meia altura da laje; (4) A influência dos alvéolos preenchidos com concreto e com reforço deve ser desprezada neste modelo; (5) $V_{R d, f i}$ é a resistência ao cisalhamento sob situação de incêndio; e (6) $V_{R d}$ é a resistência ao cisalhamento na temperatura ambiente dada pelo modelo de tensão de cisalhamento simplificada.

Figura 3- Classe de resistência ao fogo de lajes alveolares
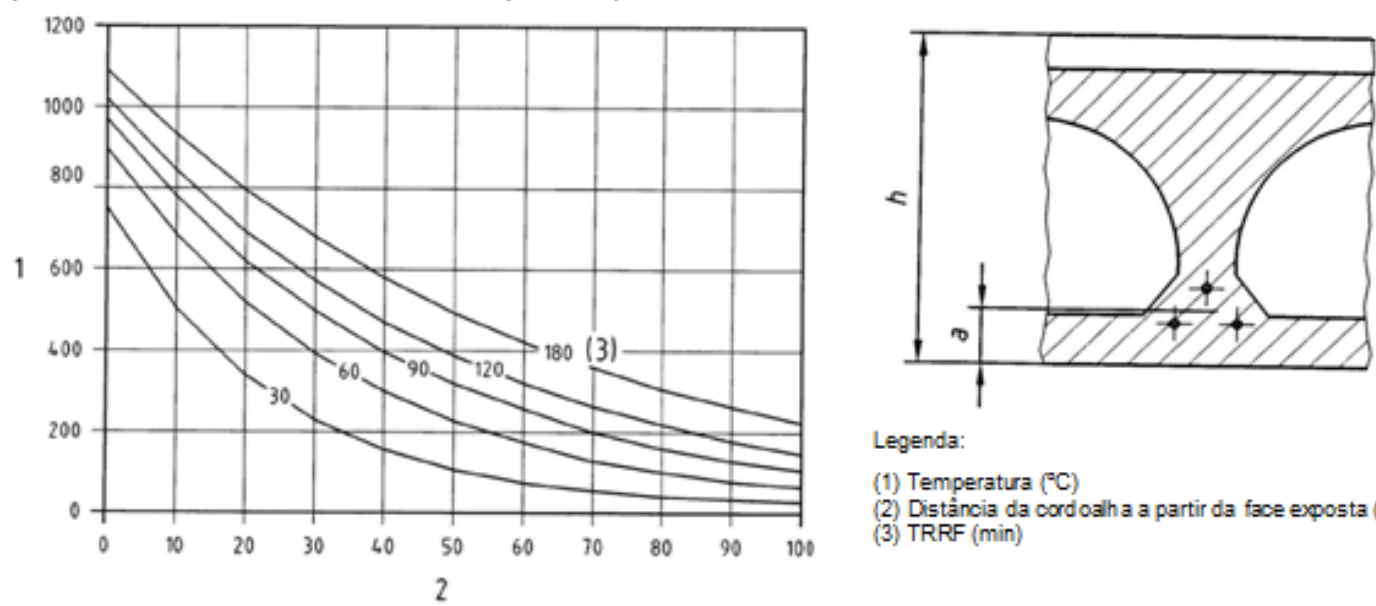

Legenda:

(1) Temperatura ("C)

(2) Distáncia da cordoah a a partir da face exposta (a) (mm)

(3) TRRF (min)

Fonte: European Committee for Standardization (2004).

Figura 4- Resistência ao fogo de lajes alveolares
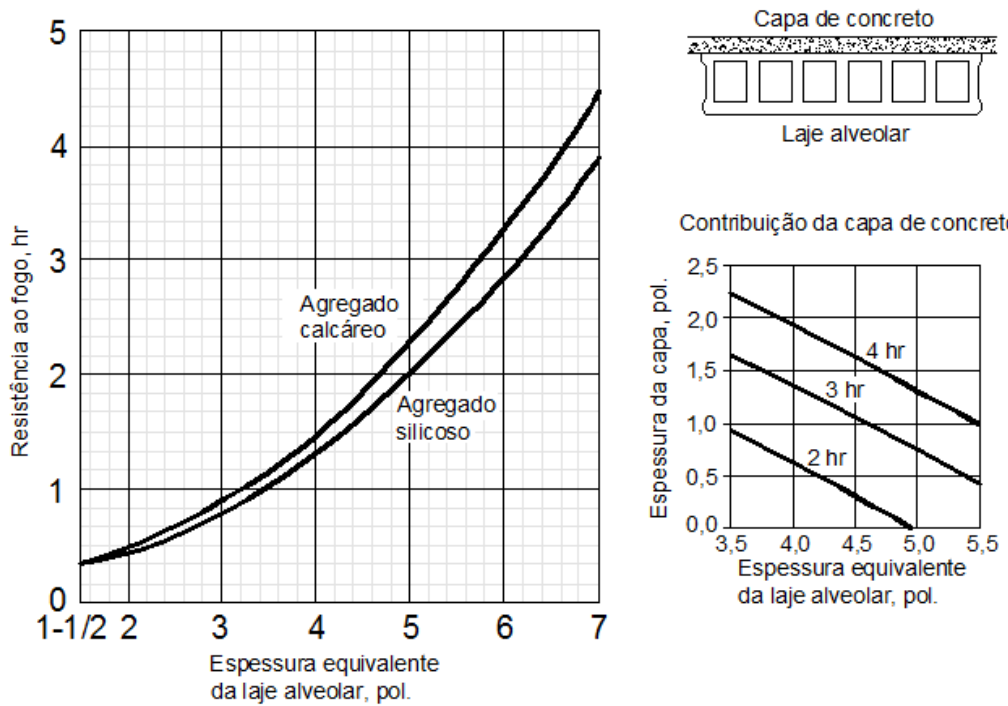

Contribuição da capa de concreto

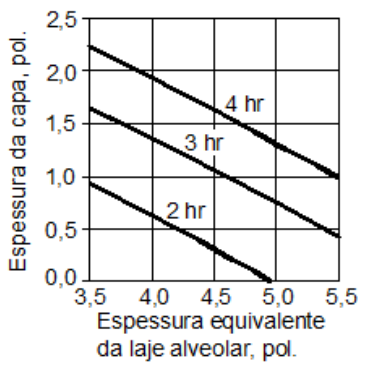

Fonte: adaptado de Prestressed Concrete Institute (1998). 


\section{Estruturas isentas de verificação}

A norma NBR 14432 (ABNT, 2001) lista condições (Tabela 3) que isentam as estruturas da verificação em projeto da condição imposta por um incêndio.

Para a adoção das isenções propostas pela normaé necessário observar as exigências quanto às medidas de proteção ativa contra o incêndio hidrantes, chuveiros automáticos e brigada de incêndio - e quanto às medidas de proteção passiva - compartimentação e saídas de emergência -, conforme as normas e regulamentos de órgãos públicos vigentes.

Em caso de não haver meios arquitetônicos de compartimentação de uma área por meio de portas e paredes corta-fogo, deve-se adotar para a edificação a classificação mais rigorosa com relação à segurança contra incêndio, como em shoppings, aeroportos, rodoviárias e galpões de múltiplos usos.

De acordo com a norma NBR 14432 (ABNT, 2001), cobertura é o fechamento superior da edificação, inclinado em no máximo $70^{\circ} \mathrm{em}$ relação à horizontal, que não apresenta características de piso. Os elementos estruturais que a compõem estão isentos dos requisitos de resistência ao fogo, exceto quando seu colapso comprometer a estabilidade da estrutura principal ou quando a cobertura da edificação tiver função de piso, mesmo que seja para saída de emergência.

Ainda de acordo com a norma, edificação térrea é uma edificação de apenas um pavimento, podendo possuir um piso elevado, como um mezanino, com área inferior ou igual à terça parte da área do piso situado no nível de descarga. Como mostrado na Tabela 3, a utilização de sistemas de chuveiros automáticos isenta qualquer edificação com essas características.

Tabela 3 - Características das edificações isentas de verificação de resistência ao fogo

\begin{tabular}{|c|c|c|c|c|c|}
\hline $\begin{array}{l}\text { Área total do piso } \\
\text { da edificação }\end{array}$ & Uso & $\begin{array}{l}\text { Carga de } \\
\text { incêndio } \\
\text { específica }\end{array}$ & Altura & $\begin{array}{l}\text { Meios de } \\
\text { proteção }\end{array}$ & Obs. \\
\hline$\leq 750 \mathrm{~m}^{2}$ & Qualquer & Qualquer & Qualquer & Mínimo ${ }^{8}$ & \\
\hline$\leq 1.500 \mathrm{~m}^{2}$ & Qualquer & $\leq 1000 \mathrm{MJ} / \mathrm{m}^{2}$ & $\leq 2 \mathrm{pav}$ & Mínimo ${ }^{8}$ & \\
\hline Qualquer & $\begin{array}{l}\text { Centros esportivos } \\
\text { Terminais de passageiros } \\
\text { Construcões provisórias }\end{array}$ & Qualquer & $\leq 23 \mathrm{~m}$ & Mínimo $^{8}$ & Nota 2 \\
\hline Qualquer & Garagens abertas ${ }^{3}$ & Qualquer & $\leq 30 \mathrm{~m}$ & Mínimo8 & \\
\hline Qualquer & Depósitos & Baixa $^{4}$ & $\leq 30 \mathrm{~m}$ & Mínimo 8 & \\
\hline Qualquer & Qualquer & $\leq 500 \mathrm{MJ} / \mathrm{m}^{2}$ & $\leq 30 \mathrm{~m}$ & Mínimo ${ }^{8}$ & \\
\hline Qualquer & Industrial $^{5}$ & $\leq 1.200 \mathrm{MJ} / \mathrm{m}^{2}$ & Térrea & Mínimo 8 & \\
\hline Qualquer & Depósitos $^{5}$ & $\leq 2.000 \mathrm{MJ} / \mathrm{m}^{2}$ & Térrea & Mínimo ${ }^{8}$ & \\
\hline Qualquer & Qualquer & Qualquer & Térrea & $\begin{array}{l}\text { Chuveiros } \\
\text { Automáticos }\end{array}$ & \\
\hline$\leq 5.000 \mathrm{~m}^{2}$ & Qualquer & Qualquer & Térrea & Mínimo ${ }^{8}$ & Nota 7 \\
\hline
\end{tabular}

Fonte: NBR 14432 (2001).

Nota: (1) Circo e assemelhados; (2) As cargas de incêndio específicas para uso conjunto com as prescrições do Anexo A encontram-se no Anexo C da NBR 14432 (ABNT, 2001); (3) Ver item 3.8 da NBR 14432 (ABNT, 2001); (4) Edificações que armazenam tijolos, pedras, areias, cimentos, metais e outros materiais incombustíveis; (5) Observados os critérios de compartimentação constantes nas normas brasileiras em vigor ou, em sua falta, regulamentos de órgãos públicos; (6) Dimensionado conforme as normas NBR 10897 e NBR 13792; (7) Com pelo menos duas fachadas de aproximação que perfaçam no mínimo 50\% do perímetro. Segundo Vargas e Silva (2003), a fachada de aproximação é a fachada da edificação localizada ao longo de uma via pública ou privada, com largura livre maior ou igual a $6 \mathrm{~m}$, sem obstrução, que possibilita o acesso e o posicionamento adequado dos equipamentos de combate. A fachada deve possuir pelo menos um meio de acesso ao interior do edifício e não ter obstáculos; e (8) Meios de proteção mínimos por lei ou regulamento vigente.

Observações gerais: (a) As estruturas térreas, ou os elementos estruturais, estão isentas da verificação ante o incêndio, exceto quando:os elementos de cobertura da edificação tiverem função de piso, mesmo que seja para saída de emergência; e a estrutura da edificação, a critério do responsável técnico pelo projeto estrutural, for essencial à estabilidade de um elemento de compartimentação. (b) As estruturas em geral estão isentas da verificação ante o incêndio, exceto quando não atenderem às exigências listadas acima e quando os ocupantes tenham restrição de mobilidade, como no caso de hospitais, asilos e penitenciárias; (c) Edificações abrangidas pela norma NBR 14432 (ABNT, 2001) devem possuir saídas de emergência conforme a norma NBR 9077; e (d) 0 elemento estrutural confinado está livre da ação do incêndio, desde que o confinamento tenha resistência ao fogo pelo menos igual à que seria exigida para o elemento. 
As fundações não apresentam problemas devido ao fato de estarem enterradas, tendo assim uma boa proteção diante do fogo (CÁNOVAS, 1988).

Deve-se atentar que, para a realização de um projeto seguro ante um incêndio, o responsável técnico deverá ter um discernimento apurado para realizar esse tipo de avaliação. Por exemplo, para uma edificação térrea com grande área de piso, onde a propagação do incêndio é maior quando comparada a uma estrutura compartimentada com múltiplos pavimentos, a norma posiciona-se de forma mais branda, podendo até mesmo isentar a estrutura desse tipo de verificação. Logo, a avaliação do técnico responsável pelo projeto é imprescindível e indispensável, tendo em vista o valor agregado da edificação ou dos materiais que ela abrigará.

\section{Conclusão}

Apesar de a norma NBR 15200 (ABNT, 2012) ter sido revisada e ficado mais completa com relação à edição anterior, ainda existem pontos que podem ser analisados e acrescentados. Desse modo, foram aqui apresentados alguns desses pontos e oferecido um ponto de partida para discussões e futuras pesquisas.

A carência de trabalhos nacionais específicos sobre o tema é uma realidade. Há a possibilidade da utilização dos internacionais, porém isso pode causar imprecisões de cálculos,já que estes se baseiam em misturas de concreto que podem ter características diferentes das dos utilizadosnacionalmente.

Do mesmo modo, a utilização dos ábacos internacionais também traz imprecisões. Como exemplo, há os ábacos de lajes alveolares que não especificam as dimensões dos alvéolos e das mesas superior e inferior, mesmo sabendo que esses fatores influenciarão na análise ao fogo do elemento.

Diante disso, o sistema estrutural em concreto prémoldado possui grande vantagem em situação de incêndio. Isso se deve ao controle tecnológico realizado em fábrica, como verificações regulares da resistênciado concreto,verificações constantes com relação à proteção da armadura com cobrimentos adequados e controle dos agregados devido a seu teor de umidade.

Buchanan (2002) comenta que durante os últimos 30 anos várias estruturas de concreto protendidoforam expostas a incêndios e, mesmo assim, poucas teriam sofrido danos graves, sendo a maioria recuperada e colocada em serviço logo após o incêndio. Portanto, em edificações que possuem análise e dimensionamento estrutural que respeitem as condições impostas, há menor risco de colocar vidas e patrimônios em perigo.

Por fim, as pesquisas sobre o tema mostraram que há uma escassez maior quando se trata de assuntos mais específicos, tais como consolos em situação de incêndio, modo de reparo ou substituição dos elastômeros no pós-incêndio e vigas com aberturas na alma em situação de incêndio. Esses assuntos, entre outros propostos no trabalho, são exemplos para temas de trabalhos futuros que envolvam o sistema construtivo em concreto pré-moldado em situação de incêndio.

\section{Referências}

ALBUQUERQUE, G. B. M. L. et al. Determinação do Momento Fletor Resistente de Vigas de Concreto Armado em Situações de Incêndio: comparação entre métodos simplificados e avançados. In: CONGRESSO BRASILEIRO DE CONCRETO, 54., Maceió, 2012. Anais... Maceió, 2012.

AMERICAN SOCIETY FOR TESTING AND MATERIALS. ASTM E 119: standard tests for fire tests of building construction and materials. Philadelphia, 1995.

\section{ASSOCIAÇÃO BRASILEIRA DE NORMAS}

TÉCNICAS. NBR 6118: projetos de estruturas de concreto: procedimento. Rio de Janeiro, 2014.

ASSOCIAÇÃO BRASILEIRA DE NORMAS TÉCNICAS. NBR 8681: ações e segurança nas estruturas: procedimento. Rio de Janeiro, 2004.

\section{ASSOCIAÇÃO BRASILEIRA DE NORMAS} TÉCNICAS. NBR 14432: exigências de resistência ao fogo de elementos construtivos de edificações: procedimento. Rio de Janeiro, 2001.

ASSOCIAÇÃO BRASILEIRA DE NORMAS TÉCNICAS. NBR 15200: projeto de estruturas de concreto em situação de incêndio. Rio de Janeiro, 2012.

BRASIL. Lei n. 4.150, de 21 de novembro de 1962, Institui o regime obrigatório de preparo e observância das normas técnicas nos contratos de obras e compras do serviço público de execução direta, concedida, autárquica ou de economia mista, através da Associação Brasileira de Normas Técnicas e dá outras providências. Diário Oficial da União, Brasília, DF, 21 nov. 1962.

BRASIL. Lei n. 8.078, de 11 de setembro de 1990, dispõe sobre a proteção do consumidor e dá outras providências. Diário Oficial da União, Brasília, DF, 12 set. 1990. 128 (176 supl):1.

BUCHANAN, A. H. Structural Design For Fire Safety. Chichester: Wiley, 2002. 
CÁNOVAS, M. F. Patologia e Terapia do Concreto Armado.São Paulo: Pini, 1988.

CASTRO, A. L.; TIBA, P. R. T.; PANDOLFELLI, V. C. Fibras de Polipropileno e Sua Influência no Comportamento de Concretos Expostos a Altas Temperaturas: revisão. Cerâmica, São Paulo, v. 57, n. 341, p. 22-31, mar. 2011.

COSTA, C. N. Dimensionamento de Elementos de Concreto Armado em Situação de Incêndio.2008. 401 f. Tese (Doutorado em Engenharia Civil) - Escola Politécnica, Departamento de Engenharia de Estruturas e Geotécnica, São Paulo, 2008.

DEL CARLO, U. A Segurança Contra Incêndio no Brasil. In: SEITO, A. I. et al. A Segurança Contra Incêndios no Brasil. São Paulo: Projeto, 2008.

EL DEBS, M. K. Concretopré-Moldado: fundamentos e aplicações. 382 f. São Carlos:Universidade de São Paulo, 2000. Projeto Reenge.

\section{EUROPEAN COMMITTEE FOR}

STANDARDIZATION. EN 1991-1-2: eurocode 1: actions on structures: part 1.2: general actions: actions on structures exposed to fire. Brussels, 2002.

\section{EUROPEAN COMMITTEE FOR}

STANDARDIZATION. EN 1992-1-2: eurocode 2: design of concrete structures: part 1.2: general rules: structural fire design. Brussels, 2004.

\section{EUROPEAN COMMITTEE FOR}

STANDARDIZATION. EN 1168:2005+A1:

precast concrete products: hollow core slabs. Brussels, 2008.

\section{FÉDÉRATION INTERNATIONALE DU} BÉTON. Fire Design of Concrete Structures: materials structures and modeling.Lausanne: FIB, 2007. (Bulletin d'information; 38).

FÉDÉRATION INTERNATIONALE DU BÉTON. Structural Connections For Precast Concrete Buildings. Lausanne: FIB, 2008. (Bulletin d'information; 43).

KIRCHHOF, L. D. et al. Análise da Influência do Teor de Umidade no Fenômeno de Spalling Explosivo em Amostras de Concreto Expostas a Elevadas Temperaturas. In: CONGRESSO BRASILEIRO DE CONCRETO, 53., Florianópolis, 2011. Anais... Florianópolis, 2011.
MORENO JUNIOR, A. L.; MOLINA, J. C. Considerações de Interesse Sobre a Avaliação em Laboratório de Elementos Estruturais em Situação de Incêndio: contribuições à revisão da NBR 5628:2001. Ambiente Construído, Porto Alegre, v. 12, n. 4, p. 37-53, out./dez. 2012.

PRESTRESSED CONCRETE INSTITUTE. Manual For the Design of Hollow Core Slabs. 2. ed. Chicago: PCI, 1998.

PRESTRESSED CONCRETE INSTITUTE.

Design Handbook: precast and prestressed concrete. 7. ed. Chicago: PCI, 2010.

POLÍCIA MILITAR DO ESTADO DE SÃO PAULO. Corpo de Bombeiros. Instrução Técnica n. 08: resistência ao fogo dos elementos de construção. São Paulo, 2001. 12 f. Disponível em: <http://www.corpodebombeiros.sp.gov.br/normas tecnicas/its_2011/INSTRUCAO_TECNICA_082011.pdf>. Acesso em: 17 jan. 2013.

POLÍCIA MILITAR DO ESTADO DE SÃO

PAULO. Decreto n. 56.819, que institui o Regulamento de Segurança contra Incêndio das edificações e áreas de risco no Estado de São Paulo e estabelece outras providências. São Paulo, 2011. Disponívem em:

<http://www.ccb.policiamilitar.sp.gov.br/credencia mento/downloads/Decreto_Estadual_56819.pdf >. Acesso em: 10 mar. 2015.

\section{PRESTRESSED CONCRETE INSTITUTE.}

Design for Fire Resistance of Precast/Prestressed Concrete. 3. ed. Chicago: PCI, 2011.

PURKISS, J. A. Fire Safety Engineering Design of Structures. 2. ed. Burlington: Elsevier, 2007.

SILVA, V. P. Projeto de Estruturas de Concreto em Situação de Incêndio: conforme ABNT NBR 15200:2012. São Paulo: Blucher, 2012.

SOUZA, A. A. A. de; MORENO JR, A. L. Efeito de Altas Temperaturas na Resistência à Compressão, Resistência à Tração e Módulo de Deformação do Concreto. Revista Ibracon de Estruturas e Materiais, São Paulo, v. 3, n. 4, p. 432-448, dez. 2010.

VARGAS, M. R.; SILVA, V. P. Resistência ao Fogo das Estruturas de Aço: manual da construção em aço. Rio de Janeiro:Centro Brasileiro da Construção em Aço, 2003.

\section{Agradecimentos}

A Leonardi Construção Industrializada pelo apoio. 


\section{Cassiano da Silva Zago}

Leonardi Construção Industrializada Ltda. | Rodovia Dom Pedro I, km 69,000 ao fim, Jardim Brogotá | Atibaia - SP - Brasil | CEP 12954-260 | Tel.: (11) 4416-5200 | E-mail: cassiano.zago@gmail.com

\section{Armando Lopes Moreno Junior}

Departamento de Estruturas, Faculdade de Engenharia Civil, Arquitetura e Urbanismo | Universidade Estadual de Campinas | Av. Albert Einstein, 951, Cidade Universitária Zeferino Vaz, Barão Geraldo | Campinas - SP - Brasil | Caixa-Postal 6021 | CEP $13083-852$ | Tel.: (19) 3521-2363 Ramal 12363 | E-mail: almoreno@fec.unicamp.br

\section{Marcelo Cuadrado Marin}

Escola de Engenharia de São Carlos | Universidade de São Paulo | Av. Trabalhador São-Carlense, 400 | São Carlos - SP - Brasil | CEP 13566-590 | Tel.: (16) 3373-9479 | E-mail: marcelo@leonardi.com.br

\section{Revista Ambiente Construído}

Associação Nacional de Tecnologia do Ambiente Construído

Av. Osvaldo Aranha, $99-3^{\circ}$ andar, Centro

Porto Alegre - RS - Brasil

$$
\text { CEP } 90035-190
$$

Telefone: +55 (51) 3308-4084

Fax: +55 (51) 3308-4054

www.seer.ufrgs.br/ambienteconstruido

E-mail: ambienteconstruido@ufrgs.br 